\title{
Urgences
}

\section{Un film de Godard}

\section{Alice Brousseau}

Numéro 20, mai 1988

Appellation contrôlée

URI : https://id.erudit.org/iderudit/025462ar

DOI : https://doi.org/10.7202/025462ar

Aller au sommaire du numéro

Éditeur(s)

Urgences

ISSN

0226-9554 (imprimé)

1927-3924 (numérique)

Découvrir la revue

Citer ce document

Brousseau, A. (1988). Un film de Godard. Urgences, (20), 11-12.

https://doi.org/10.7202/025462ar

Ce document est protégé par la loi sur le droit d'auteur. L'utilisation des services d'Érudit (y compris la reproduction) est assujettie à sa politique d'utilisation que vous pouvez consulter en ligne.

https://apropos.erudit.org/fr/usagers/politique-dutilisation/
Cet article est diffusé et préservé par Érudit.

Érudit est un consortium interuniversitaire sans but lucratif composé de l’Université de Montréal, l'Université Laval et l'Université du Québec à Montréal. Il a pour mission la promotion et la valorisation de la recherche. https://www.erudit.org/fr/ 


\section{ALICE BROUSSEAU Un film de Godard}

Nous parlons d'elle et de lui sans les nommer. Nous les regardons vivre, bouger. Il pourrait s'agir de personnages de Duras. Il pourrait s'agir de nous.

Elle parle. Elle affirme beaucoup en multipliant les gestes qui sèment le doute.

Après la question habituelle "est-ce bien cela l'amour?», il improvise une réponse. Il se perd dans les détails des livres auxquels il revient sans cesse. Il se perd dans l'anonymat. Il cherche la bonne réplique, la phrase qu'il aurait soulignée dans le premier chapitre d'un livre, quelques heures à peine après son lancement; celle qui bouleverserait le cours de notre vie parce qu'il nous semblerait tout à coup qu'elle parle si fort de nous que nous ne pouvons pas ne pas l'entendre.

Un livre entre elle et lui sur la table.

Celle qui lit: C'est par l'anonymat des personnages que je suis interpelée. C'est en cela qu'ils me ressemblent. Comme moi, transitoires. Avec juste assez d'absence pour que j'apparaisse entre les mots.

Celui qui lit: Ici, tout de notre histoire s'obscurcit. Nous n'y sommes presque plus. Interchangeables. J'ai beau mettre ma voix sur le mot "passion» ou le mot «rencontre", l'image fuit. Ne reste que des sons désertés, sans prise. Voilà où j'en suis avec la voix de l'Autre. Inévitable et pourtant étrangère.

Le livre entre elle et lui déplacé, puis replacé.

Ce matin-là, entre les tasses de café et les cigarettes, nous regardons la lenteur de nos gestes, nous entendons les mots isolés qui nous échappent. En plein drame, nous allons sourire au moment où tu diras: Comme dans un film de Godard. Exactement. Nous nous promenons de fiction en fiction avec un léger accent théâtral, avec cette fausseté dans la voix qui finit toujours par nous attendrir. Nous savons qu'il y a là quelque chose de vrai, de si vrai.

«Est-ce bien cela l'amour?» Nos doutes partiront de là. Et du livre que tu reprends, que tu consultes à nouveau malgré l'image fuyante. 
Nous sommes là, distants et anonymes, des reflets de fiction. Des personnages. C'est à ce moment-là que nous parlons le plus justement de nous. 